Pediat. Res. 8: 621-627 (1974)

Assisted ventilation

hypoxia neonate

respiratory distress syndrome

\title{
Mass Spectrometer Evaluation of Ventilation- Perfusion Abnormalities in Respiratory Distress Syndrome
}

\author{
Carl E. Hunt, ${ }^{27]}$ Sadi Matalon, O. Douglas Wangensteen, and Arnold S. Leonard \\ Departments of Pediatrics, Physiology, and Surgery, University of Minnesota, Minneapolis, Minnesota, USA
}

\begin{abstract}
Extract
Mass spectrometers should have unique advantages in the evaluation of $\dot{V} A / \dot{Q}$ [20] inequalities in neonatal respiratory distress syndrome (RDS), especially, in neonates requiring assisted ventilation. The purposes of this report are to (I) describe a method for continuous measurement of respired gas composition utilizing a mass spectrometer system, and (2) describe the results of serial aADCO ${ }_{2}$ and $\mathrm{AaDO}_{2}$ (expressed as $\left.\dot{Q}_{s} / \dot{Q}\right)$ measurements in 63 neonates with RDS.

The mass spectrometer system utilized is a mobile unit which includes the following components: quadrupole mass spectrometer for gas analysis, flow meter, and an analogue computer for measurement of respiratory flows and volumes.

In 17 patients not requiring assisted ventilation, initial $\mathrm{aADCO}_{2}$ levels ranged from normal $(<5)$ to $26 \mathrm{~mm} \mathrm{Hg}$; there was considerable variation in initial $\dot{Q}_{\mathbf{s}} / \dot{\mathbf{Q}}$. In 46 patients requiring assisted ventilation, $\dot{Q}_{s} / \dot{Q}$ measurements did not distinguish pulmonary from nonpulmonary deaths or survivors from nonsurvivors. Serial aADCO $\mathrm{CO}_{2}$ measurements, however, indicated a correlation between ability to achieve an $\mathrm{aADCO}_{2}<10 \mathrm{~mm} \mathrm{Hg}$ by age 7-10 days and potential for pulmonary survival.
\end{abstract}

\section{Speculation}

Full utilization of a mass spectrometer system will allow for breath-by-breath measurement of $\mathrm{AaDO}_{2}, \mathrm{CO}_{2}$, and $\mathrm{N}_{2}$, as well as a variety of respiratory flows and volumes. Such measurements should provide further understanding of $\dot{V A} / \dot{Q}$ inequalities in RDS. Serial $\mathrm{aADCO}_{2}$ levels may provide a more objective measurement of acute severity as well as a better definition of potential for pulmonary survival.

\section{Introduction}

Mass spectrometers have been available for over 20 years and numerous reports have described their use for respiratory and blood gas measurements [2, 18]. Although not applied previously to measurement of $\dot{\mathrm{VA}} / \dot{\mathrm{Q}}$ inequalities in neonatal respiratory disorders, a mass spectrometer system would have unique advantages, especially in neonates who require assisted ventilation.
The purposes of this report are to (1) describe a method for continuous measurement of respired gas composition utilizing a mass spectrometer system (PFA-5 [21]) and (2) describe the results of serial $\mathrm{aADCO}_{2}$ and $\mathrm{AaDO}_{2}$ measurements in 63 neonates with RDS. Although quantitative assessment of $\dot{\mathrm{VA}} / \dot{\mathrm{Q}}$ non-uniformities, the primary cause of hypoxemia in RDS, is difficult, the magnitude of $\dot{V A} / \dot{Q}$ abnormalities can be estimated from measurements of $\mathrm{ADCO}_{2}$ and $\mathrm{AaDO}_{2}$. 


\section{Materials and Methods}

The PFA-5 is a mobile unit which includes the following components: quadrupole mass spectrometer for gas analysis, hot film anemometer flow meter for flow measurements, and an analogue computer for calculation of $\mathrm{V}_{\mathrm{T}}, \mathrm{O}_{2}$ consumption, $\mathrm{CO}_{2}$ production, and other respiratory parameters.

Flow measurements are achieved by directing expired gas into the inlet of the flow meter. In children not old enough to accept the mouthpiece, flow measurements can still be obtained if the patient is intubated. Flow measurements cannot be performed in patients receiving continuous positive airway pressure (CPAP) [4] because of the flow of noninspired air through the system. Flow measurements in patients receiving intermittent positive pressure breathing (IPPB) (22) or positive end-expira-
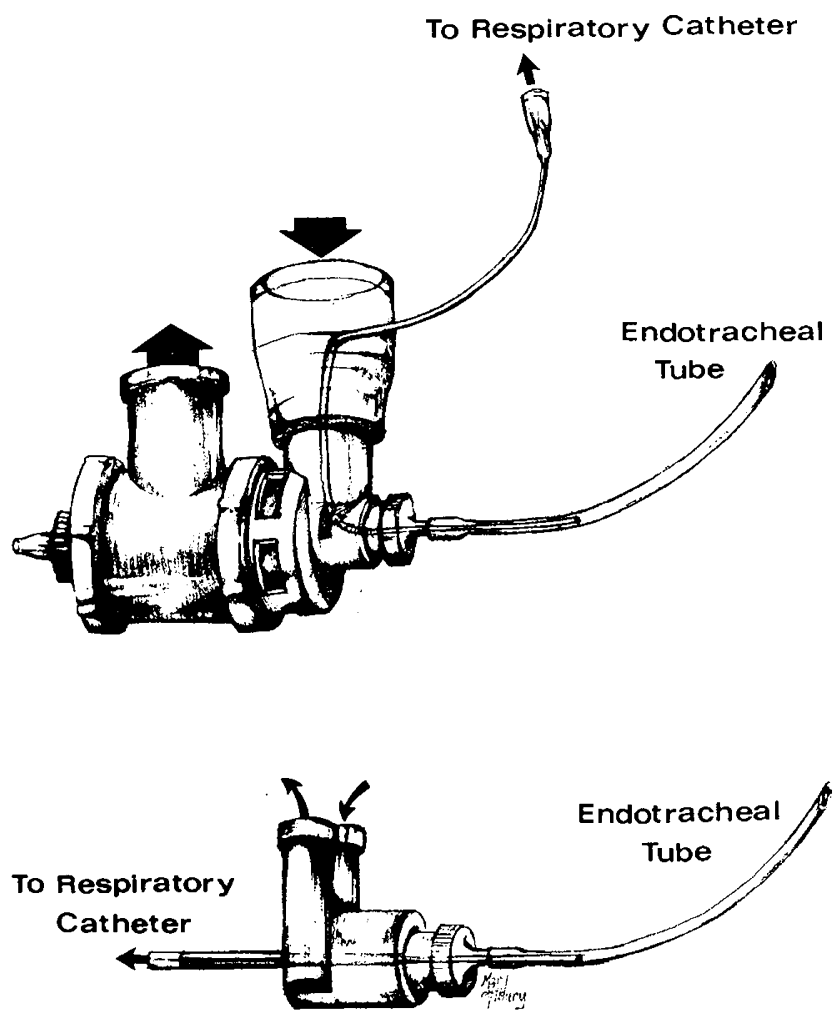

Fig. 1. Two methods of obtaining end-tidal gases have been utilized depending on the specific respirator circuit used. By either method, the reduction in internal diameter of the endotracheal (ET) tube is less than 25\%. Upper: gas collector head: A small polyethylene catheter has been inserted through the rubber connector into the proximal one-third of the ET tube. Lower: Wye infant adapter: In our currently used circuit, the gas collector head is at a distance from the ET tube. A small metal cannula has been inserted through the top of this adaptor into the proximal one-third of the ET tube. tory pressure assistance combined with IPPB (PEEP) [11] are achieved by using a gas collector head [23] or Wye infant adaptor [24] and connecting the expired air tubing to the flow meter inlet. The breath-by-breath $\mathrm{V}_{\mathrm{T}}$, obtained by integrating the flow signal during each respiratory cycle, appears as a digital read-out on the upper front panel of the PFA-5. A graphic output can also be obtained.

For gas analysis, the $99 \%$ response time of the system is approximately $500 \mathrm{~ms}$. Although its stability is excellent, the total drift/ $24 \mathrm{hr}$ being less than $\pm 2 \%$ of the gas concentration, calibration is ordinarily repeated before each measurement. Respiratory gas sampling is achieved using a $200-\mathrm{cm}$ long catheter with an internal diameter $0.3 \mathrm{~mm}$. The catheter is heated to $80^{\circ}$ to prevent water vapor condensation. The sampling rate through the catheter is about $22 \mathrm{cc} / \mathrm{min}$.

Respired gas is sampled continuously by placing the tip of the respiratory catheter at the nose or mouth in patients breathing spontaneously or at the proximal end of the endotracheal tube in intubated patients (Fig. 1). $\mathrm{O}_{2}, \mathrm{CO}_{2}$, and any other three gases with a molecular weight from 2 to 99 atomic mass units can be measured simultaneously. As with $V_{T}$, concentration of the dry gases is displayed on the digital voltmeters on the front panel of the PFA-5, and a graphic output can also be obtained (Fig. 2).

$\mathrm{AaDO}_{2}$ and $\mathrm{aADCO}_{2}$ were obtained by matching the alveolar (end-tidal) value for each gas with a simultaneous arterial value measured by conventional methods [25]. The arterial sample was obtained from the descending aorta, if an umbilical arterial catheter was in place, or from a percutaneous arterial puncture. No AaD measurements were performed unless the patients were normothermic, had stable acid-base balance, and had no acute complications or stresses such as lobar atelectasis or pneumothorax. $\mathrm{pa}_{\mathrm{O}_{2}}$ was converted to saturation using Gomez's formula [3], and $\dot{Q}_{\mathrm{s}} / \dot{Q}$ was calculated by the standard equation. Since arteriovenous $\mathrm{O}_{2}$ saturation differences of $10 \%$ in severe to $15 \%$ in mild RDS have been reported [12], we arbitrarily assumed a value of $13 \%$ for our calculations.

\section{Patient Selection}

If normothermic and at least 3 hours of age, patients were considered to have RDS when, in the absence of any other cardiopulmonary disorders, at least three of the following were present: (1) respiratory rate $>60$ breaths/min, (2) Silverman score $>4.0$ [13], (3) cyanosis in room air, (4) roentgenographic evidence of RDS.

Of the approximately 175 RDS newborns admitted to 
our NICU each year, all but 5-10\% are born elsewhere and most are referred for admission only when a need for assisted ventilation is anticipated. Because of this selection of more severe RDS, the incidence of RDS requiring assisted ventilation in 1972, for example, was $66 \%$. Survival for RDS patients in 1972 was $41 \%$ for those who required assistance as compared with $95 \%$ for those who did not require assistance, with an overall survival of $59 \%$.

Assisted ventilation included any combination of CPAP, IPPB, or PEEP [6]. The indications for assisted ventilation consisted routinely of one or more of the following: (1) apnea or slow, gasping inadequate respirations, (2) totally opacified lung fields by thoracic roentgenogram, or (3) at an $\mathrm{FI}_{\mathrm{O}_{2}}$ of $\geq 0.9$, a $\mathrm{pa}_{\mathrm{O}_{2}}$ of $<60 \mathrm{~mm}$ $\mathrm{Hg}$ if under $12 \mathrm{hr}$ of age, or $<40 \mathrm{~mm} \mathrm{Hg}$ at any age. Patients were initially started on CPAP and changed to a respirator when spontaneous ventilation could not be maintained and/or an $\mathrm{FI}_{\mathrm{O}_{2}}$ of $>0.60$ was required. PEEP was used in preference to IPPB whenever an $\mathrm{FI}_{\mathrm{O}_{2}}$ of $>0.30$ was required with IPPB. As the clinical condition then improved, $\mathrm{FI}_{\mathrm{O}_{2}}$ was gradually decreased to $\leq 0.30$ while maintaining $\mathrm{pa}_{\mathrm{O}_{2}}$ at $50-70 \mathrm{~mm} \mathrm{Hg}$, and the end-expiratory pressure (EEP) was then gradually reduced from 10 to $0 \mathrm{~cm} \mathrm{H}_{2} \mathrm{O}$. If at all possible, ventilation was always adjusted so as to maintain $\mathrm{pa}_{\mathrm{CO}_{2}}$ at 40-50 mm Hg. When patients were successfully weaned from PEEP, CPAP was begun at an $\mathrm{FI}_{\mathrm{O}_{2}}$ of $\leq 0.30$ and EEP of 6-10 $\mathrm{cm} \mathrm{H}_{2} \mathrm{O}$, while maintaining $\mathrm{pa}_{\mathrm{O}_{2}}$ at $40-60$ $\mathrm{mm} \mathrm{Hg}$; the EEP was then gradually decreased to 0 as tolerated.

Beginning in mid-1972, $\mathrm{AaDO}_{2}$ and $\mathrm{ADCO}_{2}$ measurements have been obtained in 120 RDS patients who required assisted ventilation and in 70 who did not require assistance. The patients included in this report are the 46 who required assisted ventilation and 17 without assistance for whom serial measurements of $\mathrm{aADCO}_{2}$ and $\mathrm{AaDO}_{2}$ are available. In the nonassisted patients, the mean birth weight was $2.42 \mathrm{~kg}$ ( \pm 1.08 ); all $17 \mathrm{pa}-$ tients survived. Among the 46 patients who required assistance, the mean birth weight was $2.17 \mathrm{~kg}$ ( \pm 0.57 ) for the 28 survivors and $1.48 \mathrm{~kg}( \pm 0.53)$ for the 18 nonsurvivors.

\section{Results}

\section{$a \mathrm{ADCO}_{2}$}

Nonassisted $R D S$. Serial $\mathrm{aADCO}_{2}$ changes were assessed in 17 patients who did not require assisted ventilation (Fig. 3). Because these patients were often not admitted until they approached $24 \mathrm{hr}$ of age, the initial
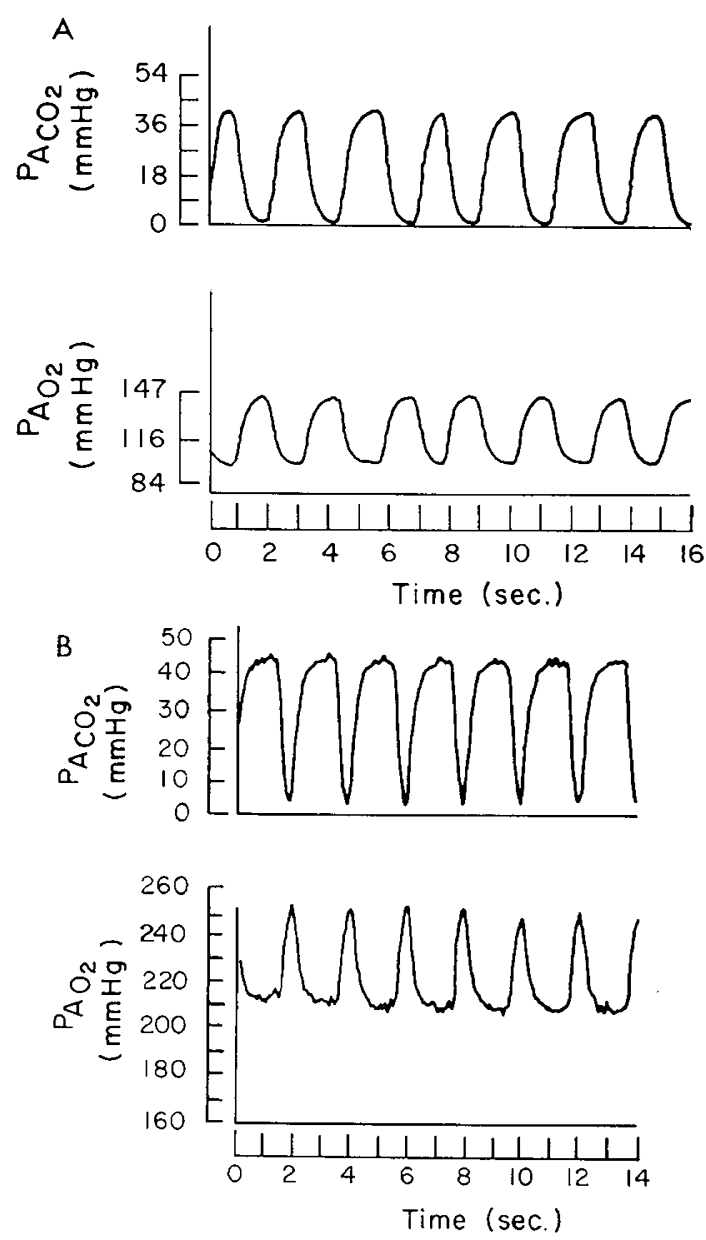

Fig. 2. Actual tracings of end-tidal $\mathrm{pCO}_{2}$ and $\mathrm{pO}_{2}$ in two neonates with respiratory distress syndrome (RDS). $A$; tracing obtained in nonassisted RDS patient $\left(\mathrm{FI}_{\mathrm{O}_{2}}, 0.28\right)$. The end-expiratory plateaus indicate that alveolar (end-tidal) gas concentrations are being measured. $B$ : tracing obtained in assisted RDS patient currently requiring intermittent positive pressure breathing ( $\mathrm{FI}_{\mathrm{O}_{2}} 0.40$ ). Representative end-expiratory plateaus can be visualized easily. End-inspiratory plateaus were not achieved because of a short inspiratory duration (330 ms).

aADCO 2 usually could not be obtained early enough to reflect the observed changes in clinical symptoms and adequacy of ventilation that occurred before age $24 \mathrm{hr}$.

The initial $\mathrm{AADCO}_{2}$ varied from normal $(<5)$ up to $26 \mathrm{~mm} \mathrm{Hg}$. In all but three patients, $\mathrm{aADCO}_{2}$ gradually improved with age as the clinical condition improved. Although the three remaining patients did improve after age 4 days, unfortunately, no later $\mathrm{aADCO}_{2}$ levels were obtained.

Assisted RDS. Serial aADCO $\mathrm{ADC}_{2}$ changes were assessed in 36 patients who required assisted ventilation (Fig. 4), all but three of whom initially required PEEP. Eighteen of these 36 patients survived, 14 died from problems re- 


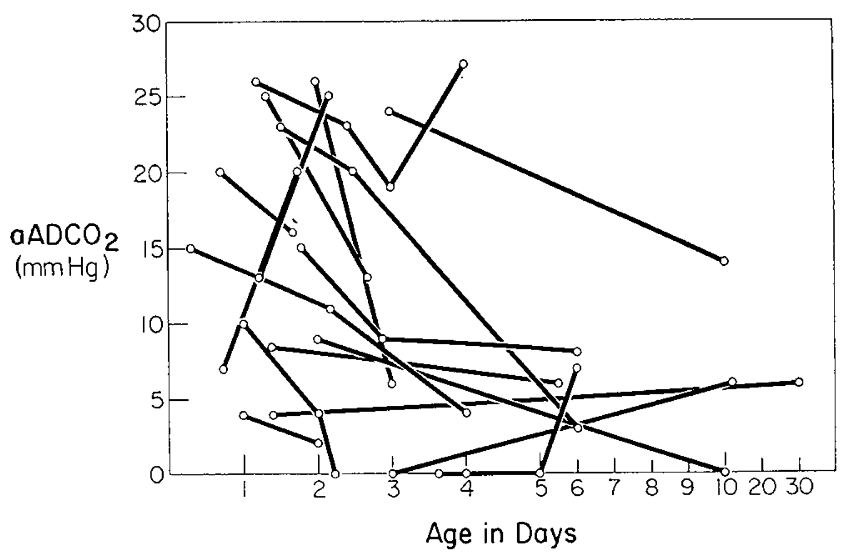

Fig. 3. Serial changes in $\mathrm{aADCO}_{2}$ in 17 respiratory distress syndrome patients who did not require assisted ventilation. Although $\mathrm{aADCO}_{2}$ gradually improved in six of the nine patients with initial levels $>10 \mathrm{~mm} \mathrm{Hg}$, later $\mathrm{aADCO}_{2}$ measurements were not obtained in the other three patients. In all three, however, there was gradual clinical improvement after age 4 days.

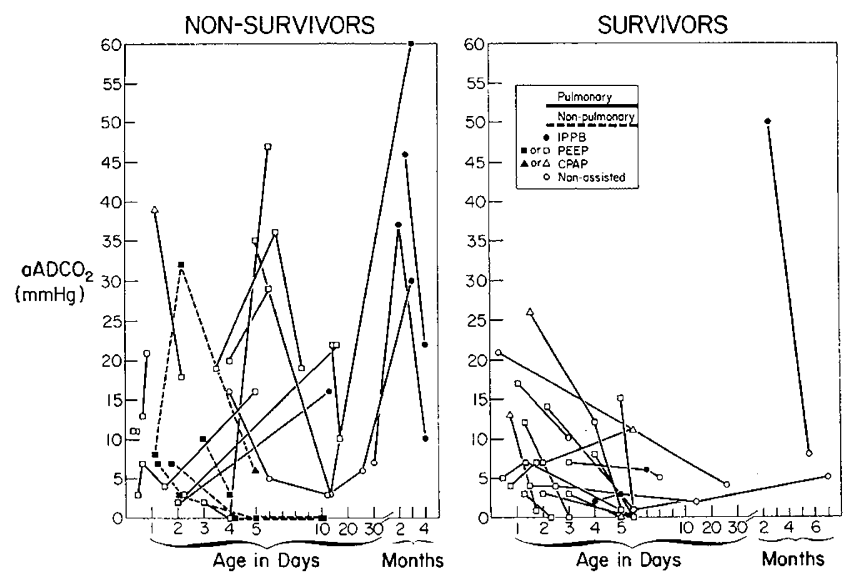

Fig. 4. Serial $\mathrm{aADCO}_{2}$ changes in 36 respiratory distress syndrome patients who required assisted ventilation. The mode of assistance is indicated for each $\mathrm{aADCO}_{2}$ measurement. Left: serial measurements of aADCO 2 in 18 nonsurvivors. In 4 , death was secondary to nonpulmonary problems; $\mathrm{aADCO}_{2}$ values in these 4 tended to be more typical of pulmonary survivors than of nonsurvivors. Right: serial measurements of $\mathrm{aDCO}_{2}$ in 18 survivors. Unlike the nonsurvivors, an $\mathrm{aADCO}_{2}$ of $<10 \mathrm{~mm} \mathrm{Hg}$ was usually achieved by age 5-6 days.

lated to severe RDS, and 4 died of nonpulmonary problems. Although the nonpulmonary deaths are included with the other nonsurvivors, $\mathrm{aADCO}_{2}$ values in these 4 were more consistent with values obtained in the pulmonary survivors. The mode of assisted ventilation at the time of each $\mathrm{aACCO}_{2}$ measurement is indicated.

Individual initial $\mathrm{aADCO}_{2}$ values were not appreciably different from those obtained in nonassisted RDS, except that assisted ventilation was required in order to achieve these comparable levels. In the 18 survivors of severe $\mathrm{RDS}, \mathrm{aADCO}_{2}$ values of $<10 \mathrm{~mm} \mathrm{Hg}$ were typically achieved by age 5 to 6 days, whereas, in the pulmonary nonsurvivors, $\mathrm{aADCO}_{2}$ tended to either remain at, or later return to, a level of $\geq 10 \mathrm{~mm} \mathrm{Hg}$. Except for one older infant with a superimposed severe pneumonitis, failure to achieve and maintain an $\mathrm{aACCO}_{2}$ of $<10 \mathrm{~mm} \mathrm{Hg}$ by age 7-10 days even with maximal ventilatory assistance was associated with ultimate pulmonary nonsurvival.

\section{$\mathrm{AaDO}_{2}$}

Nonassisted RDS. Serial $\mathrm{AaDO}_{2}$ changes, expressed as $\dot{\mathrm{Q}}_{\mathrm{s}} / \dot{\mathrm{Q}}$, were assessed in 16 patients not requiring assisted ventilation (Fig. 5). As with $\mathrm{aADCO}_{2}$, not enough measurements were obtained in the first $24 \mathrm{hr}$ of life to define the precise age at which maximal $\dot{Q}_{s} / \dot{Q}$ is achieved. There was considerable variation in initial $\dot{\mathrm{Q}}_{\mathrm{s}} / \dot{\mathrm{Q}}$. In 10 patients, $\dot{\mathrm{Q}}_{\mathrm{s}} / \dot{\mathrm{Q}}$ improved with age as the clinical condition improved. Although the other 6 patients later showed progressive clinical improvements, unfortunately no later $\dot{Q}_{\mathrm{S}} / \dot{\mathrm{Q}}$ measurements were obtained.

Assisted RDS. Serial measurements of $\mathrm{AaDO}_{2}$, expressed as $\dot{Q}_{s} / \dot{Q}$, were obtained in 46 patients who required assisted ventilation (Fig. 6); all but 3 required PEEP during the acute illness. Of these 46 patients, 28 survived, 14 died of RDS-related problems, and 4 died of nonpulmonary problems.

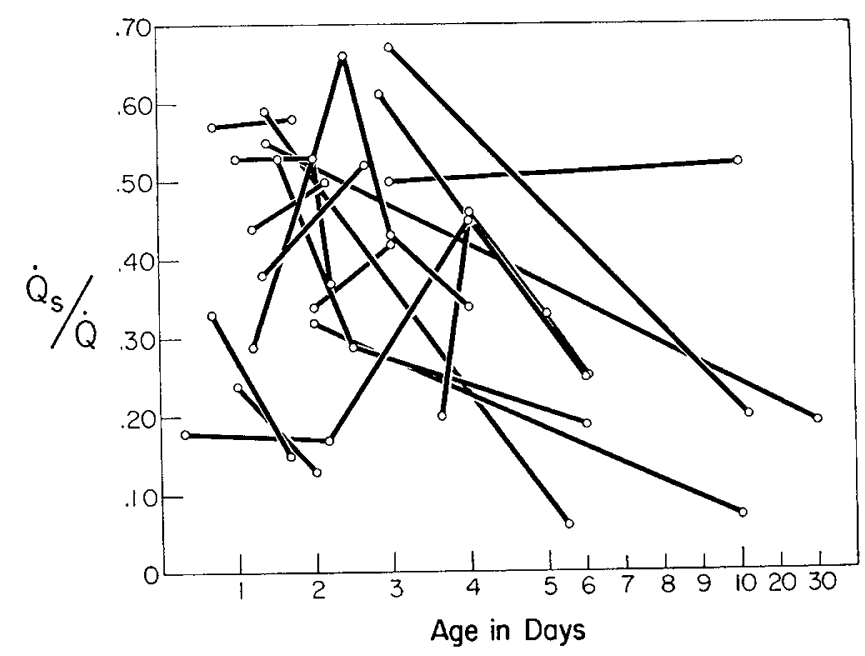

Fig. 5. Serial measurements of $\dot{Q}_{s} / \dot{Q}$ in 16 respiratory distress syndrome patients who never required assisted ventilation. There was considerable variation in initial $\dot{Q}_{s} / \dot{Q}$. 

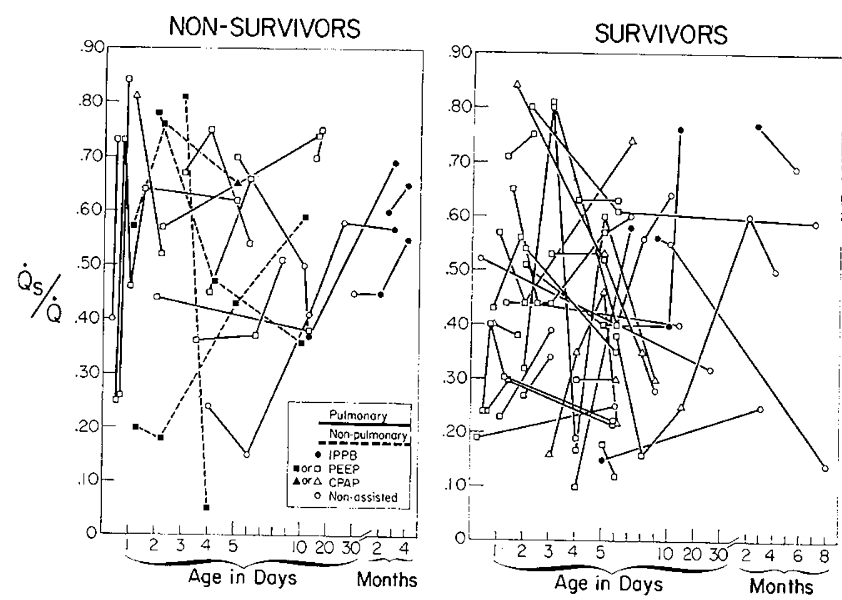

Fig. 6. Serial $\dot{Q}_{s} / \dot{Q}$ changes in 46 respiratory distress syndrome patients who required assisted ventilation. The mode of assistance is indicated for each measurement. Left: serial changes in the 18 nonsurvivors, 4 of whom died of nonpulmonary problems. $\dot{Q}_{s} / \dot{Q}$ values were not appreciably different in the nonpulmonary as compared with the pulmonary deaths. Right: serial $\dot{Q}_{\mathrm{s}} / \dot{Q}$ changes in the 28 survivors. No trend is evident that would allow for separation of survivors from nonsurvivors.
As in nonassisted RDS patients, there was considerable variation in $\dot{Q}_{s} / \dot{Q}$ measurements. Unlike a $\mathrm{ADCO}_{2}$, these serial $\dot{Q}_{\mathrm{s}} / \dot{Q}$ measurements did not indicate any trends that would distinguish pulmonary from nonpulmonary deaths or survivors from nonsurvivors.

\section{Serial Measure of Ventilatory Variables}

The PFA-5 was also used to obtain a more detailed assessment of serial aADCO, $\mathrm{AaDO}_{2}$, and $\dot{\mathrm{Q}}_{\mathrm{s}} / \dot{\mathrm{Q}}$ changes in the early acute phase of RDS. Expressed as a function of age, $\mathrm{FI}_{\mathrm{O}_{2}}$, inspiratory pressure and rate, and EEP, the serial observations obtained in a representative survivor and pulmonary nonsurvivor are illustrated in Fig. 7. PEEP was required from $11 \mathrm{hr}$ to 7.5 days of age in the survivor. In the pulmonary nonsurvivor, PEEP was required from age $4 \mathrm{hr}$ until his death at age 5.2 days, $7 \mathrm{hr}$ after the last measurement.

No measurements before beginning PEEP were obtained in either patient. In both patients, peak severity of RDS was attained between 12 and 18 hr of age. Subsequently, aADCO${ }_{2}$ and $\dot{Q}_{s} / \dot{Q}$ then slowly decreased in

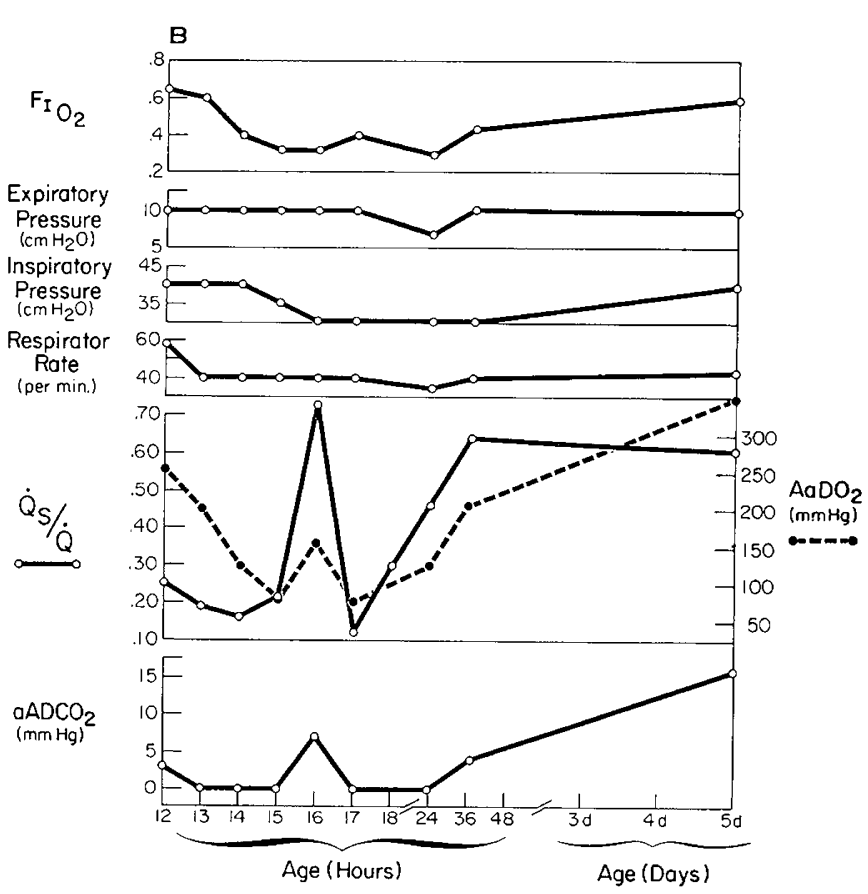

Fig. 7. Serial changes in $\mathrm{aADCO}_{2}, \mathrm{AaDO}_{2}$, and $\dot{\mathrm{Q}}_{\mathrm{s}} / \dot{\mathrm{Q}}$ as a function of age, $\mathrm{FI}_{\mathrm{O}_{2}}$, inspiratory pressure and rate, and end-expiratory pressure (EEP) in two premature infants with severe respiratory distress syndrome (RDS) requiring positive-end-expiratory pressure assistance (PEEP). A: survivor: PEEP was required at age $11 \mathrm{hr}$, and continued until 7.5 days of age. $\dot{Q}_{s} / \dot{Q}$ was maximal at $18 \mathrm{hr}$ and then gradually decreased. aADCO 2 during the first $24 \mathrm{hr}$ of assistance ranged from 4 to $7 \mathrm{~mm} \mathrm{Hg}$; the subsequent decrease to 0 could be related to either lung improvement or to the decrease in EEP. B: nonsurvivor: PEEP was required at $4 \mathrm{hr}$ of age; death occurred at age 5.2 days. After the achievement of maximal $\dot{Q}_{s} / \dot{Q}$ and $\mathrm{aADCO}_{2}$ at $16 \mathrm{hr}$ of age, both $\mathrm{aADCO}_{2}$ and $\dot{\mathrm{Q}}_{\mathrm{s}} / \dot{\mathrm{Q}}$ subsequently decreased to low levels but then, unlike the survivor, progressively increased again thereafter. Autopsy revealed RDS and intraventricular hemorrhage. 
the survivor. In the nonsurvivor, however, after a temporary decrease to low levels, both $\mathrm{ADCO}_{2}$ and $\dot{\mathrm{Q}}_{\mathrm{s}} / \dot{\mathrm{Q}}$ increased progressively thereafter.

\section{Discussion}

Currently available methods for evaluation of respiratory function in the neonate have generally not been applicable to patients who receive assisted ventilation. Most such evaluations, therefore, have been limited to infants breathing unassisted. Since mass spectrometry does not have such limitations, its application to neonatal respiratory disorders should have unique advantages and benefits. In patients of any age or disease of any degree of clinical severity, breath-by-breath analysis of respired gas composition can be achieved simply by placing the respiratory catheter in the expired air stream.

For gas analysis, the PFA-5 has a total response time of approximately $500 \mathrm{~ms}$. Because of faster respiratory rates and smaller $V_{T}$ in infants, a potential concern is that this response time would be too slow to allow for true end-tidal sampling, thereby overestimating $\mathrm{pA}_{\mathrm{O}_{2}}$ and underestimating $\mathrm{pA}_{\mathrm{CO}_{2}}$. As illustrated (Fig. 2), however, true end-expiratory plateaus can generally be achieved even though inspiratory duration may be $<500$ $\mathrm{ms}$ and an accurate analysis of end-inspiratory $\mathrm{pO}_{2}$ and $\mathrm{pCO}_{2}$ cannot be obtained.

Obtaining $\mathrm{pa}_{\mathrm{O}_{2}}$ samples representative of pulmonary venous blood is another potential concern. Since the arterial sample used for $\mathrm{AaDO}_{2}$ measurements was ordinarily obtained from an umbilical arterial catheter positioned in the lower thoracic aorta, at least during the first 48-72 hr of life, $\mathrm{AaDO}_{2}$ would be overestimated if right-to-left shunts through the foramen ovale and/or ductus arteriosus (fetal shunts) are also present. Since fetal shunts seldom persist beyond 48-72 hr of age, however, and are seldom significant in those with severe RDS [7] (in which case a large intrapulmonary $\dot{Q}_{s} / \dot{Q}$ is already present $[10,19])$, it is not likely that $\dot{Q}_{s} / \dot{Q}$ has been overestimated significantly in our patients with severe RDS. Although the magnitude of the overestimation can be expected to be greater in mild (nonassisted) as compared with severe (assisted) RDS, significant differences in $\dot{Q}_{s} / \dot{Q}$ as measured from pulmonary vein and descending aorta have not generally occurred after 3 days of age [7]. Inasmuch as the arteriovenous $\mathrm{pCO}_{2}$ difference is only $4-6 \mathrm{~mm} \mathrm{Hg}$, a $\mathrm{ADCO}_{2}$ is essentially unaffected by fetal shunts, and blood from the descending aorta, therefore, should always be representative of pulmonary venous blood.

The $\mathrm{AaDO}_{2}$ data have been presented as intrapulmonary $\dot{Q}_{s} / \dot{Q}$ because less variability exists than when just $\mathrm{AaDO}_{2}$ values are presented. The use of $\dot{\mathrm{Q}}_{\mathrm{s}} / \dot{\mathrm{Q}}$ rather than $\mathrm{AaDO}_{2}$ has been justified on theoretical grounds [16] using a digital computer model of the lung for estimation of $\mathrm{AaDO}_{2}$ and $\dot{Q}_{\mathrm{s}} / \dot{Q}$ for varying $\mathrm{FI}_{\mathrm{O}_{2}}$ values and for lungs with varying degrees of $\dot{\mathrm{VA}} / \dot{Q}$ nonuniformity [17]. These computer results indicate that, in a lung with constant $\dot{\mathrm{VA}} / \dot{\mathrm{Q}}$ characteristics, $\mathrm{AaDO}_{2}$ values will vary widely with $\mathrm{FI}_{\mathrm{O}_{2}}$, but $\dot{\mathrm{Q}}_{s} / \dot{\mathrm{Q}}$ will remain relatively constant within an $\mathrm{FI}_{\mathrm{O}_{2}}$ range of $0.2-0.8$. Because changes in $\mathrm{AaDO}_{2}$ result primarily from changes in $\mathrm{FI}_{\mathrm{O}_{2}}$, therefore, utilization of $\dot{\mathrm{Q}}_{\mathrm{s}} / \dot{\mathrm{Q}}$ provides a better indication of actual changes within the lung itself.

The $\mathrm{aADCO}_{2}$ and $\mathrm{AaDO}_{2}$ data obtained in these RDS patients provides additional confirmation of (1) the presence of low $\dot{\mathrm{VA}} / \dot{\mathrm{Q}}$ regions in the lung, accounting for the intrapulmonary $\dot{Q}_{s} / \dot{Q}[5,14-15,19]$, and (2) the presence of high $\dot{\mathrm{VA}} / \dot{\mathrm{Q}}$ regions, as indicated by elevated $\mathrm{aADCO}_{2}$ levels. In addition to the information which could be derived from serial $\mathrm{AaDN}_{2}$ measurements [ 1 , 8, 9], further conclusions regarding $\dot{\mathrm{VA}} / \dot{\mathrm{Q}}$ inequalities in RDS will require earlier and more frequent measurements of $\mathrm{AaD}$ than was achieved in the patients reported here.

Evaluation of the RDS patient who cannot be weaned from assisted ventilation has been a major clinical problem. No objective method for assessing respiratory function in these patients has been available. Although $\mathrm{AaDO}_{2}$ measurements do not appear to be helpful at the present time, our data indicates a correlation between ability to achieve an $\mathrm{aADCO}_{2}$ of $<10 \mathrm{~mm} \mathrm{Hg}$ by age 7-10 days and pulmonary survival. Ongoing studies are in progress to further evaluate the prognostic significance of $\mathrm{aADCO}_{2}$ in the acute as well as in the convalescent phase of RDS.

\section{Summary}

A mass spectrometer system capable of simultaneous, continuous measurement of any five respiratory gases in patients of any age or clinical condition has been utilized for measurement of $\mathrm{pA}_{\mathrm{CO}_{2}}$ and $\mathrm{pA}_{\mathrm{O}_{2}}$.

$\dot{\mathrm{VA}} / \dot{\mathrm{Q}}$ inequalities have been evaluated in 63 patients by serial assessments of $\mathrm{AADCO}_{2}$ and $\mathrm{AaDO}_{2}$ (expressed as $\left.\dot{Q}_{\mathrm{s}} / \dot{\mathrm{Q}}\right)$ in assisted as well as nonassisted patients. Our preliminary data indicates that $\mathrm{ADCO}_{2}$ levels may be of significance in defining potential for pulmonary survival in RDS patients.

\section{References and Notes}

1. FARHI, L. E.: Ventilation-perfusion relationship and its role in alveolar gas exchange. In: C. H. Caro: Advances in Respira- 
tory Physiology, p. 148 (The Williams \& Wilkins Co., Baltimore, 1966).

2. Fowler, K. T.: The respiratory mass spectrometer. J. Phys. Med. Biol., 14: 185 (1969).

3. Gomez, D. M.: Considerations of $\mathrm{O}_{2}$-hemoglobin equilibrium in the physiological state. Amer. J. Physiol., 200: 135 (1961).

4. Gregory, G. A., Kitterman, J. A., Phibbs, R. H., Tooley, W. H., and Hamilton, W. K.: Treatment of the idiopathic respiratory distress syndrome with continuous positive airway pressure. New Engl. J. Med., 284: 1333 (1971).

5. Harrod, K. R., L'Heureux, P., Wangensteen, O. D., and Hunt, C. E.: Long term follow-up of severe respiratory distress syndrome treated with IPPB. J. Pediat., 84. (1974).

6. Hunt, C. E. : Effects of combined inspiratory and expiratory positive pressure for critical respiratory distress syndrome. Pediat. Res., 6: 410/150 (1972).

7. Hunt, C. E.: Magnitude and duration of fetal shunts in the acute phase of respiratory distress syndrome (Unpublished data).

8. Krauss, A. N., Soodalter, J. A., and Auld, P. A. M.: Adjustment of ventilation and perfusion in the full-term normal and distressed neonate as determined by urinary alveolar nitrogen gradients. Pediatrics, 47: 865 (1971).

9. Markello, R., Winter, P., and OlszowkA, A.: Assessment of ventilation-perfusion inequalities by arterial-alveolar nitrogen differences in intensive care patients. Anesthesiology, 37. 4 (1972)

10. Murdock, A. I., And Swyer, P. R.: The contribution to venous admixture by shunting through the ductus arteriosus in infants with the respiratory distress syndrome of the newborn. Biol. Neonatorum, 13: 194 (1968).

11. Nuerenberg, D. V., And Kassow, E. A.: Method of achieving positive end-expiratory pressure (PEEP) with Bennett PR-1 and PR-2 respirators. Resp. Care, 16: 284 (1971).

12. Rudolph, A. M., Drorbaugh, J. E., and Auld, P. A. M., et. al: Studies on the circulation in the neonatal period: The circulation in the respiratory distress syndrome. Pediatrics, 27: 551 (1961)

13. Silverman, W. A., and Andersen, D. H.: A controlled clinical trial of effects of $\mathrm{H}_{2} \mathrm{O}$ mist on obstructive respiratory signs, death rate and necropsy findings among premature infants. Pediatrics, 17: 1 (1956).

14. Thibeault, D. W., Poblete, E., and Auld, P. A. M.: Alveolar-arterial oxygen difference in premature infants breathing $100 \%$ oxygen. J. Pediat., 71: 814 (1967).

15. Tori, C. A., Krauss, A. N., ANd Auld, P. A. M.: Serial studies of lung volume and $\dot{\mathrm{VA}} / \dot{\mathrm{Q}}$ in hyaline membrane disease. Pediat. Res., 7: 82 (1973).

16. Wangensteen, O. D., and Matalon, S.: Unpublished data.

17. WeSt, J. B.: Ventilation-perfusion inequality and overall gas exchange in computer models of the lung. Resp. Physiol., 7: 88 (1969).

18. WoldRING, S.: Biomedical applications of mass spectrometry for monitoring partial pressures. J. Ass. Advan. Med. Instrument., 4: 43 (1970).

19. Woodrum, D. E., Oliver, T. K., and Hodson, W. A.: The effect of prematurity and hyaline membrane disease on oxygen exchange in the lung. Pediatrics, 50: 380 (1972).

20. $\dot{V A} / \dot{Q}$ : ventilation-perfusion ratio; $\mathrm{AaDO}_{2}, \mathrm{AaDCO}_{2}, \mathrm{AaDN}_{2}$ : alveolar-arterial difference for $\mathrm{O}_{2}, \mathrm{CO}_{2}$, or $\mathrm{N}_{2} ; \dot{Q}_{\mathcal{s}} / \dot{\mathrm{Q}}$ : rightto-left shunt fraction; $\mathrm{V}_{\mathrm{T}}$ : tidal volume, $\mathrm{FI}_{\mathrm{O}_{2}}$ : fractional inspired $\mathrm{O}_{2}$ concentration.

21. Pulmonary function analyzer, Automated Medical Systems, Minneapolis, Minn.

22. Done with Bennett PR-2 only in our series.

23. No. 5540, Puritan-Bennett Corporation, Kansas City, Mo.

24. No. 0686, 15/22 mm angled, Puritan-Bennett Corporation, Kansas City, Mo.

25. IL pH/gas analyzer, model 113, Instrumentation Laboratory, Inc., Boston, or Corning $\mathrm{pH}$ blood gas analyzer, model 165 Corning Scientific Instruments, Medfield, Mass.

26. This research was presented in part at Midwest Pediatric Research Society, Chicago, November, 1972, and American Academy of Pediatrics, Chicago, October, 1973, and was supported in part by Dwan Family Fund and Department of Health, Education and Welfare Grant no. HSN 110169387.

27. Requests for reprints should be addressed to: C. E. Hunt, M.D., Box 92, Department of Pediatrics, University of Minnesota Hospitals, Minneapolis, Minn. 55455 (USA).

28. Accepted for publication January 16, 1974. 